\title{
Editorials
}

\section{Supporting adults with hearing loss in primary care:}

\author{
new NICE guideline
}

Your next patient is Mrs A, an older lady you know well who has chronic heart failure, diabetes, and a long list of medications. There's so much to do in the next 10 minutes. Your task is even harder because she can't hear you clearly. You keep having to repeat yourself. She has a hearing aid but it makes a whistling noise and she frowns while she fiddles with it. You don't know much about hearing aids, and in any case there are more pressing medical issues to tackle today. Hearing loss drops off your agenda until next time. Understandable; but hearing may be near the top of Mrs A's agenda. Better hearing could transform her day-to-day quality of life, from talking on the telephone to buying her shopping or watching the TV. She won't have to worry about not hearing her name called in the surgery waiting room, nor will she need to book another appointment because she didn't hear everything you said to her.

GPs will be familiar with patients like Mrs A. It's estimated that for the average GP about four consultations a day are related to hearing loss; ${ }^{1}$ from earwax or infection, more permanent hearing loss related to ageing or noise, underlying pathology such as middle ear disease, or as part of a systemic illness such as autoimmune or neurological disease. A new National Institute for Health and Care Excellence (NICE) guideline on the management of hearing loss in adults has important, practical messages for GPs and primary care teams, which should make a real difference for our patients with this common and distressing condition. ${ }^{2}$ In this article we outline the scale of the problem, some of the key guideline recommendations relevant to GPs, and consider how we can improve GPs awareness and training in hearing loss.

\section{MAJOR IMPACT ON PUBLIC HEALTH}

Hearing loss is a major public health issue affecting about 11 million people in the UK, the majority without an occupational or other risk factor. Because the population is ageing it is estimated that by 2035 about one-fifth of the population will have hearing loss. ${ }^{2}$ The impact can be significant, with communication difficulties affecting relationships, employment, or education, leisure activities like music or social gatherings, and threatening independence.

Even a hearing loss described as 'mild' on audiometry can result in debilitating

'Hearing is central to our patients' health and wellbeing, and losing it is every bit as debilitating as losing other senses... like eyesight or balance.

problems understanding speech in background noise. Although hearing loss affects all ages, it is more prevalent in older people, and there is an association between hearing loss and cognitive performance as well as dementia: this association is more marked with more severe hearing loss. ${ }^{3}$ Hearing loss can make people feel isolated and reduce self-esteem; it also doubles the risk of developing depression and increases the risk of anxiety and other mental health issues. ${ }^{4}$

\section{EARLY REFERRAL FOR HEARING LOSS}

Research suggests that the use of hearing aids reduces these risks, ${ }^{5}$ and the guideline makes a clear statement on the clinical and cost-effectiveness of early referral for audiological assessment and consideration for hearing aids. The problem is that hearing loss is often very gradual and it can take time for people to accept they have a difficulty; one study found that on average there is a 10 -year delay in people aged $55-74$ years seeking help for their hearing loss. ${ }^{6}$ When they do come to see us, over $25 \%$ of adults who report hearing problems to their GP are not referred to NHS hearing services, perhaps because they are advised to wait until their symptoms are more severe. ${ }^{7}$ As GPs we are used to first excluding common causes of hearing loss such as impacted wax otitis externa/media, or middle ear effusion related to upper respiratory tract infections: and treating appropriately. But where there isn't an obvious or treatable cause, what then? One of the clearest recommendations in the new NICE guideline is that GPs should refer all adults, regardless of their age, who present for the first time with hearing difficulties, or in whom you suspect hearing difficulties, to audiology services for an assessment. The committee agreed that it is not good practice for a GP to delay referral for hearing difficulties until the problem is more severe.

\section{SUDDEN HEARING LOSS}

When hearing loss not explained by external or middle ear causes develops suddenly lover a period of $\leq 3$ days) within the past 30 days, the guideline says we should refer immediately (to be seen within 24 hours) to an ear, nose, and throat (ENT) service or an emergency department. This requires immediate or urgent investigation for treatable causes such as autoimmune disease, chronic infection, rapidly expanding vestibular schwannoma, or stroke. Delay in management may lead to increased morbidity. If sudden hearing loss occurred $>30$ days prior to presentation, patients still need urgent referral (to be seen within 2 weeks).

\section{HEARING LOSS AND DEMENTIA}

People with hearing loss have difficulty understanding conversation and therefore remembering; hearing loss may thus mimic dementia. The guideline suggests that we should consider referring adults with suspected or diagnosed dementia or mild cognitive impairment to an audiology service for a hearing assessment because hearing loss may be a comorbid condition. We should also consider referring adults without hearing loss but with diagnosed dementia, mild cognitive impairment, or a diagnosed learning (intellectual) disability to an audiology service for a repeat hearing assessment every 2 years.

\section{GUIDANCE ON EARWAX REMOVAL}

There is clear advice which should increase the efficiency of the roughly 2 million consultations a year in the UK for earwax removal. ${ }^{8}$ If Mrs A has earwax contributing to her hearing loss or other symptoms, or preventing examination of her ear, we should be offering to remove it for her in primary or community care. We should not be using manual syringing; electronic ear irrigation is one preferred method, so long as there are no contraindications such as eardrum perforation, ear infection, or ear surgery. We should use pre-treatment wax softeners (water is an option), which can be immediately before ear irrigation or 
for up to 5 days beforehand. Alternatively, consider microsuction or other methods of earwax removal (such as manual removal using a probel for adults in primary or community care. All procedures should only be carried out if we have the expertise, training, and right equipment.

\section{HEARING AID MAINTENANCE AND SUPPORT}

Mrs A already has a hearing aid, but it is not working properly. This may be because it is loose in her ear, or because she is unaware that it needs routine maintenance every few months. The importance of this follow-up has often not been explained in the past.

She may well benefit from having another one on the other side. There is evidence

\section{Box 1. Additional adult hearing loss resources}

\section{Resources for GPs and their practices}

Action on Hearing Loss (for GPs)

wnw.actiononhearingloss.org.uk/gp

Check your hearing: Tel: 0844800 3838; http:// uww.actiononhearingloss.org.uk/hearinghealth/check-your-hearing/

Caring for older people with hearing loss: Tips and facts for carers and staff working with older people: www.actiononhearingloss.org.uk/ heartocare

Deafness: An article for GPs. O'Brien V, Leverton T. Deafness. InnovAit 2018; 11(1): 6-13 DOI: 10.1177/1755738017732364.

Action plan on hearing loss: NHS England, DoH. Action plan on hearing loss. 2015. https://www.england.nhs.uk/wp-content/ uploads/2015/03/act-plan-hearing-loss-upd.pdf Next Generation Text A relay assistant converts speech to text between user and hearing person. https://uww.ngts.org.uk

Interpreternow (computer or app): Live webcam tool for GPs to communicate with non-English speakers, hearing impaired and profoundly deaf, sign, and foreign-language speakers; Tel: 01494687600.

https://interpreternow.co.uk

\section{Resources for people with hearing loss:} Action on Hearing Loss:

unw.actiononhearingloss.org.uk

British Tinnitus Association:

https://uww.tinnitus.org.uk

C2Hear Online: https://wnw.youtube.com/ channel/UC_CO85ih5H68q5YSxMziidw

The Ear Foundation: https://unw. earfoundation.org.uk

Hearing Link: https://www.hearinglink.org Scottish Council on Deafness: mww.scod.org.uk UK Health Professionals with Hearing Loss: hphl.org.uk

Note: Audiology and ENT departments often have local recommendations. that wearing two hearing aids can improve sound quality, help to make speech easier to understand when there is background noise, and make it easier to tell where sounds are coming from. Audiologists have been given a clear message to ensure patients are consistently supported with advice, care, and follow-up, and encouraged to discuss personal listening devices such as personal loops, personal communicators, TV amplifiers, telephone devices, and alarms.

Mrs A will be pleased to hear that the guideline highlights the importance of making sure clinics and waiting rooms are suitable for people with hearing loss, for example by reducing background noise and by making sure that all staff are trained to communicate effectively with people with hearing loss (for example by speaking clearly, not simply raising the voice).

\section{MORE TO BE DONE}

This new guideline should help to increase awareness of the importance of hearing loss among healthcare professionals and offer clear guidance on when and who to refer to specialist services. But there is much more to be done. Hearing loss does feature on the GP curriculum, and a handful of UK GP training programmes include posts in ENT, but training about hearing loss is patchy (Leverton, unpublished data on survey of UK GP specialty training, 2018). We need to develop and improve learning resources and training in hearing loss so that primary healthcare professionals start to see the issue from the patient's viewpoint and feel more confident in managing it. Even basic knowledge can make a big difference. For example, how should patients look after their aids? What resources are available for people with hearing loss other than the NICE guideline (see Box 1 for some additional suggested resources.). Hearing is central to our patients' health and wellbeing, and losing it is every bit as debilitating as losing other senses, often higher on the medical agenda, like eyesight or balance. This new guideline should go some way to improving quality of life for patients like Mrs A.

\section{Graham Easton}

GP and Senior Clinical Teaching Fellow, UCL Medical School, London.

\section{Ted Leverton,}

Retired GP, Bere Alston, Devon, and RCGP Clinical Advisor.

\section{Provenance}

Commissioned; externally peer reviewed.

\section{ADDRESS FOR CORRESPONDENCE \\ Graham Easton}

University College London Medical School, Postgraduate Medical Education, Room GF/664, Royal Free Campus, Royal Free Hospital, Hampstead, London NW3 2PR, UK.

\section{Email: g.eastonđucl.ac.uk}

\section{Competing interests}

Ted Leverton is hearing impaired and volunteers with Action on Hearing Loss. The authors were both GP members of the National Guideline Committee on Hearing Loss in Adults. The guideline was developed by the National Guideline Centre which received funding from the National Institute for Health and Care Excellence. The views expressed in this publication are those of the authors and not necessarily those of NICE.

DOI: https://doi.org/10.3399/bjgp18X699497

\section{REFERENCES}

1. Royal National Institute for the Deaf. A simple cure. A national report into the deaf and hard of hearing people's experiences of the National Health Service. London: RNID, 2004.

2. National Institute for Health and Care Excellence. Hearing loss in adults: assessment and management. NICE guideline (NG98). 2018. https://www.nice.org.uk/guidance/ng98 laccessed 1 Oct 2018).

3. Lin FR, Metter EJ, O'Brien RJ, et al. Hearing loss and incident dementia. Arch Neurol 2011; 68(2): 214-220.

4. Chisolm TH, Johnson CE, Danhauer JL, et al. A systematic review of health-related quality of life and hearing aids: final report of the American Academy of Audiology Task Force on the Health-Related Quality of Life Benefits of Amplification in Adults. J Am Acad Audiol 2007; 18(2): 151-183.

5. Ferguson MA, Kitterick PT, Chong LY, et al. Hearing aids for mild to moderate hearing loss in adults. Cochrane Database Syst Rev 2017. 9: CD012023.

6. Davis A, Smith P, Ferguson M, et al. Acceptability, benefit and costs of early screening for hearing disability: a study of potential screening tests and models. Health Technol Assess 2007; 11(42): 1-294.

7. Benova L, Grundy E, Ploubidis GB. Socioeconomic position and health-seeking behavior for hearing loss among older adults in England. J Gerontol B Psychol Sci Soc Sci 2015; 70(3): 443-452.

8. Guest J, Greener M, Robinson A, Smith A. Impacted cerumen: composition, production, epidemiology and management. QJM2004; 97(8): 477-488.

9. Schilder AG, Chong LY, Ftouh S, Burton MJ. Bilateral versus unilateral hearing aids for bilateral hearing impairment in adults. Cochrane Database Syst Rev 2017; 12: CD012665. 